$\begin{array}{cc}\text { ACADEMIA ROMÂNĂ } & \text { Rev. Roum. Chim., } \\ \text { Revo, 65(9), 801-806 } & \text { Revue Roumaine de Chimie } \\ \text { http://web.icf.ro/rrch/ } & \text { DOI: } 10.33224 / \text { rrch.2020.65.9.06 }\end{array}$

\title{
SYNTHESIS AND CHARACTERIZATION OF A NOVEL SUGAR BASED CROSS-LINKER
}

\author{
ANAMICA ${ }^{*}$ and Poorn Prakash PANDE \\ Department of Chemistry and Environmental Science, M.M.M. University of Technology Gorakhpur-273010, U.P., India
}

Received February 13, 2020

\begin{abstract}
There are very few literature reports on the synthesis of monosaccharide based cross-linkers. A novel monosaccharide sugar-based cross-linker was synthesized by using D-mannitol, and allyl chloride in basic medium at low temperature $\left(40^{\circ} \mathrm{C}\right)$ under inert atmospheric conditions. We have used a new synthetic scheme which does not involve the use of autoclave at high temperature and pressure for carrying out allylation with allyl chloride. The synthesized product has been characterized by, Fourier-transform infrared (FT-IR) spectra and ${ }^{1} \mathrm{H}$ Nuclear magnetic resonance $\left({ }^{1} \mathrm{HNMR}\right)$ spectra. The formation of allyl mannitol was also confirmed with the help of elemental analysis of $\mathrm{C}, \mathrm{H}$ and $\mathrm{O}$. Cross linked polymer gel samples were prepared by polymerizing acrylic acid monomer alongwith the synthesized cross-linker at different concentrations. Aqueous gels have been prepared from the cross-linked polymers and their swelling capacity has been studied. It has been found that these gels act as superabsorbent materials. The optimum ratio of cross-linker and acrylic acid monomer for the preparation of gel having highest swelling capacity ( $28000 \%$ of water) was found to be $0.03 \mathrm{~g}$ crosslinker with $12.0 \mathrm{~g}$. monomer.

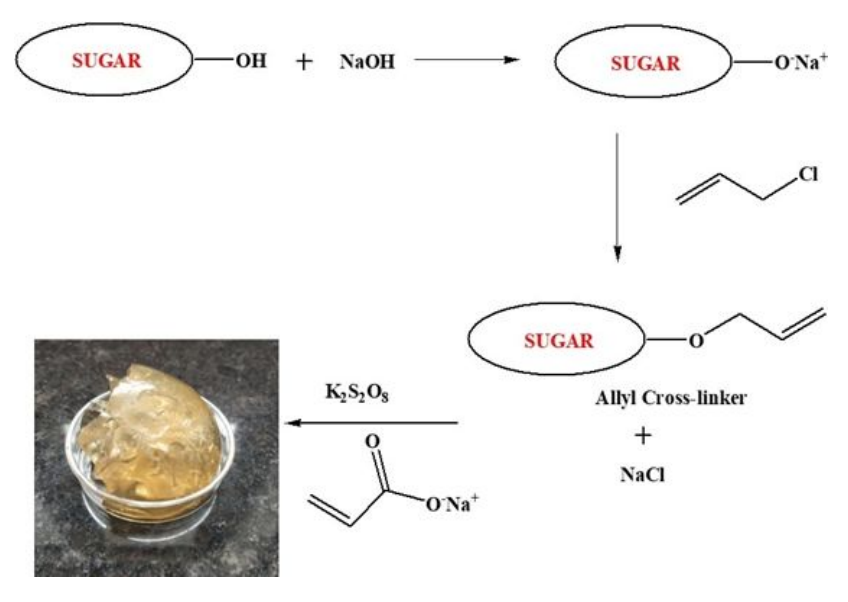

\section{INTRODUCTION}

Gels are three-dimensional cross-linked network of polymeric chains, which transport ionic groups. These are the materials, which can absorb large amount of liquids much greater than their weight under load or without load such as biological fluids. ${ }^{1}$ The gels show great potential in solving problems related to ecological, industrial and biological fields. ${ }^{2-4}$ After swelling in water gel resembles with living tissues, and can be used as biomaterial in various bio-applications. ${ }^{5}$ The potential of gels is enhanced by the linking through a variety of crosslinkers. The synthesized gels are used as a catalyst, in heavy metal removal, in dye

\footnotetext{
* Corresponding author: anamicamishra72@gmail.com

removal, in sanitary pads, in anion removal from water etc.

In the preparation of cross-linker, the natural compounds and biopolymers are commonly used. Due to their low cost and biocompatibility, these biomaterials are of much interest for the synthesis of cross-linkers for the researchers ${ }^{6,7}$ The gels can be degraded easily, which make them an excellent material in various applications. Different polysaccharides such as starch, cellulose, and chitosan have been used in the synthesis of crosslinkers. ${ }^{8-10}$ There are many literature studies about the preparation of polysaccharides-based linkers but only a few reports are available on the preparation of monosaccharides and oligosaccharides based 
crosslinking agents. ${ }^{11,12}$ Mallory Stevenson et.al. have used ribose crosslinking agent in gelatin films, ${ }^{13}$ Farnaz Mazaheri Karvandian et. al. reported glucose cross-linker in bone scaffolds, ${ }^{14}$ and David M. Hudson et. al. studied collagen cross-linking agent in bone pathobiology. ${ }^{15}$

This paper comprises the synthesis, characterization of a sugar based cross-linker allyl mannitol (AM) and preparation of polymer-gels based on this cross-linker. D-Mannitol is a type of sugar alcohol used in diabetic foods as sweetener and in medication. It is also used to reduce pressure in eyes. Naturally mannitol is isolated from sea-weed $(20 \%)$ and tree $(80 \%)$.

\section{EXPERIMENTAL}

\section{General}

D-mannitol, sodium hydroxide, allyl chloride, ethyl acetate, sodium chloride, and anhydrous sodium sulphate were purchased from SRL chem. Pvt ltd. India. The chemicals were used after purification. The solvents were used of analytical grade. The structure of the synthesised products was confirmed by elemental analysis, C, H, N and O. Elemental analysis was performed on an elemental analyser's Euro-E 3000 instrument. FT-IR Spectrometer Perkin Elmer Spectrum GX Range: $10,000 \mathrm{~cm}-1$ to $370 \mathrm{~cm}-1$ (in $\mathrm{KBr}$ discs) were used to analyse crosslinker. ${ }^{1} \mathrm{H}$ Nuclear magnetic resonance ( $\left.{ }^{1} \mathrm{HNMR}\right)$ spectra were obtained with a Bruker Advance III $400 \mathrm{MHz}$ spectrometer on samples dissolved in dimethyl sulfoxide (DMSO). The chemical shifts are given in $\delta$ (delta) from tetramethyl silane.

\section{Synthesis of Allyl Mannitol}

A $250 \mathrm{~mL}$ R.B. flask equipped with a magnetic stirring bar was taken. D-mannitol (5.469 g, $30 \mathrm{mmol})$ aqueous $\mathrm{NaOH}$
(4.8 g, $120 \mathrm{mmol}) \mathrm{NaOH}$ dissolved in $7 \mathrm{~mL}$ water) was added to the flask. The flask was sealed and heated at $80^{\circ} \mathrm{C}$ with constant stirring for 90 minutes. After that, the flask was cooled, opened and allyl chloride $(9.39 \mathrm{~g}, 120 \mathrm{mmol})$ was added and the mixture was stirred for 24 hours at $40^{\circ} \mathrm{C}$ under nitrogen atmosphere. The temperature of reaction was increased to $100^{\circ} \mathrm{C}$ for two hours. Then the contents were further stirred for 60-72 hours. Reaction mixture was cooled at room temperature, placed in an ice bath, the flask was opened and ice water was added to dissolve sodium chloride formed during the reaction. The product was extracted with ethyl acetate. The combined organic layers were washed with water and brine respectively, dried over anhydrous sodium sulphate, filtered and concentrated under reduced pressure at $40-50^{\circ} \mathrm{C}$. A pale-yellow coloured liquid was obtained. The synthesized compound allyl mannitol is $\left(\mathrm{C}_{18} \mathrm{H}_{30} \mathrm{O}_{6}\right)$ M.W. 342, Yield: 68\%. Elemental anal.: (Calc) Found \%: C (63.16) 63.12, H (8.77) 8.75, and O (28.07) 28.04.

\section{Synthesis of Polymer gel}

Acrylic acid (12 g) was dissolved in distilled water (20 $\mathrm{mL}$ ) and neutralized with $8.3 \mathrm{M}$ sodium hydroxide $(20 \mathrm{~mL})$. After that the contents were transferred into a 2-neck round bottom flask, equipped with magnetic stirring bar and fitted with condenser. The reaction is carried out in an inert $\left(\mathrm{N}_{2}\right)$ atmosphere. The desired quantity allyl cross-linking agent was added to the flask, followed by the addition of $1 \mathrm{ml}$ potassium persulfate solution $(10 \%$, KPS). The reaction mixture was placed in a water bath at $40^{\circ} \mathrm{C}$ and continuously stirred. When an exothermic reaction started, the reaction mixture was removed from water bath. The reaction was allowed to take place about two hours, for completing the reaction. The obtained gelled mass of polyacrylic acid was dried at $80^{\circ} \mathrm{C}$ for 24 hours. The dried crystal-like solid was grinded for further investigations. Similarly, different polymer gel samples were prepared using different amount of crosslinking agent.

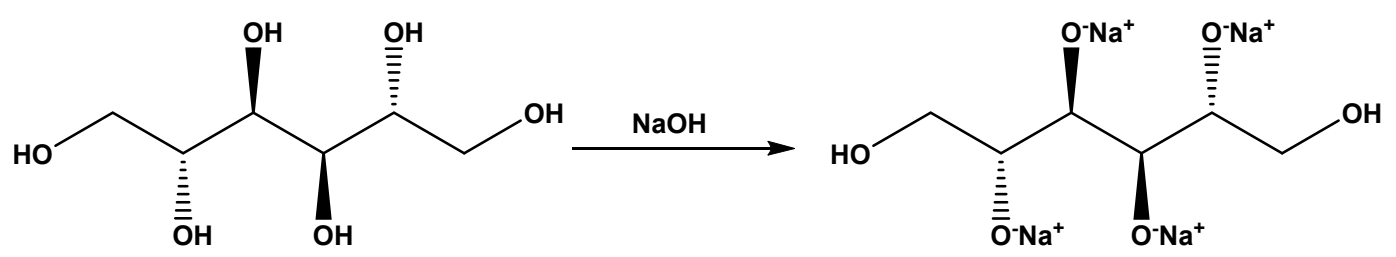<smiles>C=CCO[C@@H](CO)[C@@H](OCC=C)[C@H](OCC=C)[C@@H](CO)OCC=C</smiles>

Scheme 1 - Formation of cross-linker from D-mannitol sugar. 


\section{RESULTS AND DISCUSSION}

\section{Preface}

D-mannitol based cross-liker was synthesized from D-mannitol and allyl chloride in basic medium. The formation of product allyl mannitol (AM) was confirmed with the help of elemental analyses, FT-IR and 1HNMR spectroscopy.

\section{Study of FT-IR}

The IR spectrum of allyl mannitol is shown in Figure 1, and different absorption peaks are shown in Table 1. IR spectral data shows hydroxyl absorption band at $3419 \mathrm{~cm}^{-1}$. Absorption band at $2920 \mathrm{~cm}^{-1}$ indicates the presence of $\mathrm{C}=\mathrm{C}-\mathrm{H}$ group and stretching band at $1646 \mathrm{~cm}^{-1}$ confirm the presence of $\mathrm{C}=\mathrm{C}$ group in compound. The peaks at $1425 \mathrm{~cm}^{-1}, 1455 \mathrm{~cm}^{-1}$ show -CH- group near to double bonded carbon, and peak at $1089 \mathrm{~cm}^{-1}$ shows $-\mathrm{C}-\mathrm{O}-$ stretching. $=\mathrm{C}-\mathrm{H}$ stretching and bending peaks are at $3080 \mathrm{~cm}^{-1}, 926-994 \mathrm{~cm}^{-1}$. ${ }^{16-18}$

\section{Study of ${ }^{1}$ HNMR}

The ${ }^{1}$ HNMR spectra of allyl mannitol show the peak of different proton of allyl group as $\mathrm{H}^{\mathrm{a}}, \mathrm{H}^{\mathrm{b}}, \mathrm{H}^{\mathrm{c}}$ between $85-6$. While in the case of D-Mannitol, there are no peaks between $85-6$. The ${ }^{1} \mathrm{HNMR}$ peaks of synthesized sugar based cross-linker is shown in Figure 2. ${ }^{1} \mathrm{H}-\mathrm{NMR}$ (in deuterated DMSO): $\delta 6.0\left(\mathrm{t}, 4 \mathrm{H},=\mathrm{CH}_{\mathrm{a}}-\right), 5.34\left(\mathrm{~d}, 4 \mathrm{H},=\mathrm{CH}_{\mathrm{b}}\right)$, $5.1\left(\mathrm{~m}, 4 \mathrm{H},=\mathrm{CH}_{\mathrm{c}}\right), 4.0\left(\mathrm{~d}, 8 \mathrm{H},-\mathrm{O}-\mathrm{CH}_{2}\right), 3.94(\mathrm{~s}$, $2 \mathrm{H},-\mathrm{OH}), 3.57-3.51\left(\mathrm{~m}, 4 \mathrm{H},-\mathrm{CH}_{2}-\mathrm{OH}\right), 3.40(\mathrm{~m}$, $\left.4 \mathrm{H},-\mathrm{CH}_{2-}\right), 3.50\left(\mathrm{~m}, 4 \mathrm{H},-\mathrm{CH}_{2}-\right)$. The ${ }^{1} \mathrm{HNMR}$ data of different proton as $\mathrm{H}^{\mathrm{a}}, \mathrm{H}^{\mathrm{b}}, \mathrm{H}^{\mathrm{c}},-\mathrm{O}-\mathrm{CH}_{2}$ in linker is shown in Figure 3.

\section{Application-Gel formation}

The spectral data (IR, ${ }^{1} \mathrm{HNMR}$ ) it can be concluded that allyl groups are linked to Dmannitol group at four places (secondary $\mathrm{OH}$ group positions). Likes some other allyl crossliker, this crosslinker contain four ally groups which can be used in formation of gels. Gels have been prepared (Figure 4) by the polymerization of sodium salt of acrylic acid in the presence of potassium persulfate initiator and allyl mannitol cross-linker. In our studies these superabsorbent gels can absorb about 281 times water and 28115 $\%$ of their original weight. These gels can be used in various applications such as in personal care materials, biomaterials, drug-delivery systems, biosorbent, pharmaceutical, construction, forestation, agriculture, environmental and industrial applications. In water management, the gel is used for required and unwanted water management depending on their particular usages.

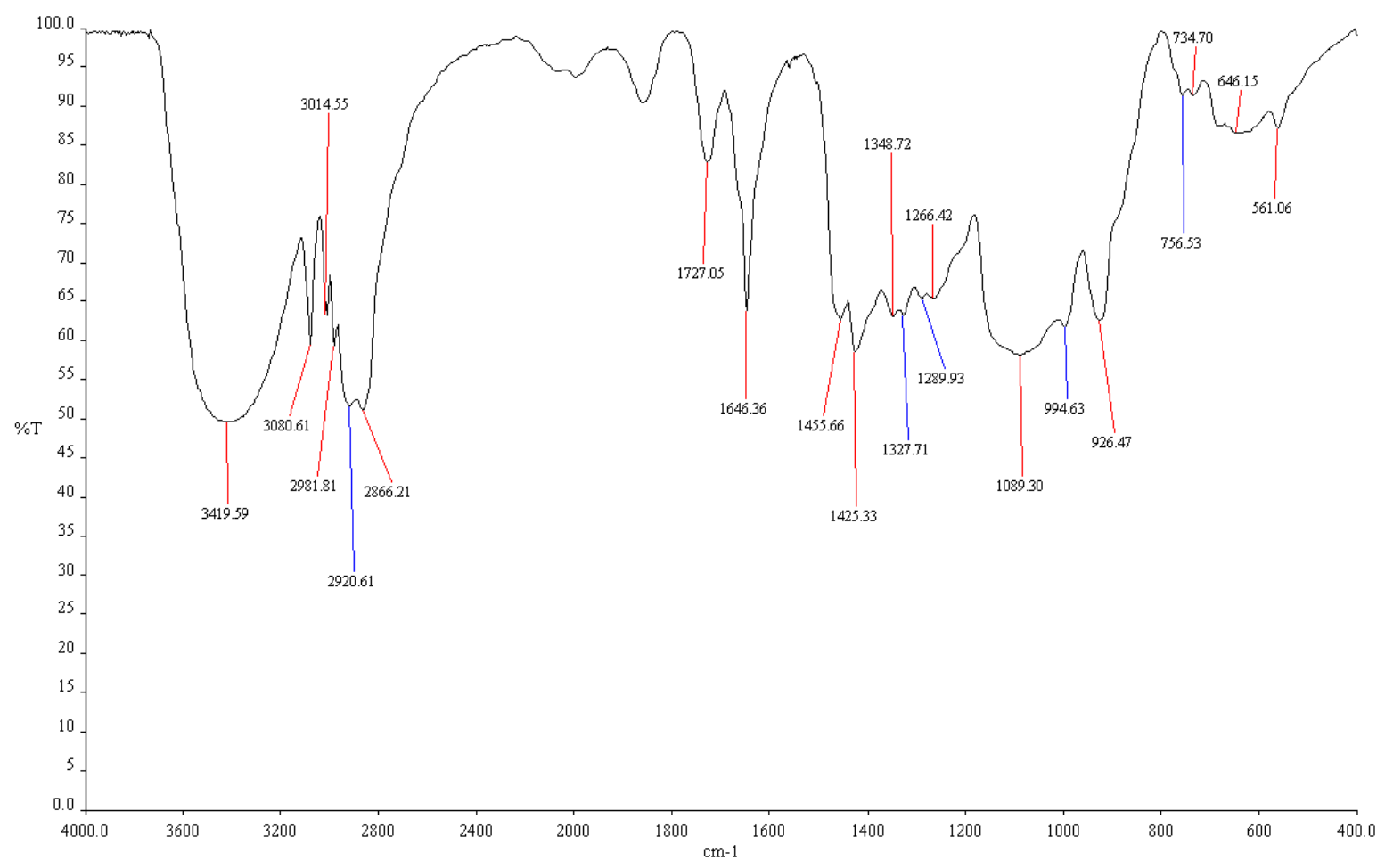

Fig. 1 - IR spectra of Allyl D-Mannitol. 
Table 1

IR Frequency of Allyl D-mannitol cross linker

\begin{tabular}{|c|c|}
\hline IR (in cm cm $\left.^{-1}\right)$ & Allyl Mannitol \\
\hline -O-H stretching & $3419 \mathrm{~cm}^{-1,16}$ \\
\hline$-\mathrm{C}=\mathrm{C}-$ & $1646 \mathrm{~cm}^{-1,17}$ \\
\hline -C-O stretching & $1089 \mathrm{~cm}^{-1,18}$ \\
\hline$=\mathrm{C}-\mathrm{H}$ Stretching & $3080 \mathrm{~cm}^{-1,17}$ \\
\hline$=\mathrm{C}-\mathrm{H}$ bending & $926-994 \mathrm{~cm}^{-1,17}$ \\
\hline$-\mathrm{C}=\mathrm{C}-\mathrm{H}$ & $2920 \mathrm{~cm}^{-1,17}$ \\
\hline$-\mathrm{C}=\mathrm{C}-\mathrm{CH}_{2}$ & $1425 \mathrm{~cm}^{-1}, 1455 \mathrm{~cm}^{-1,17}$ \\
\hline
\end{tabular}
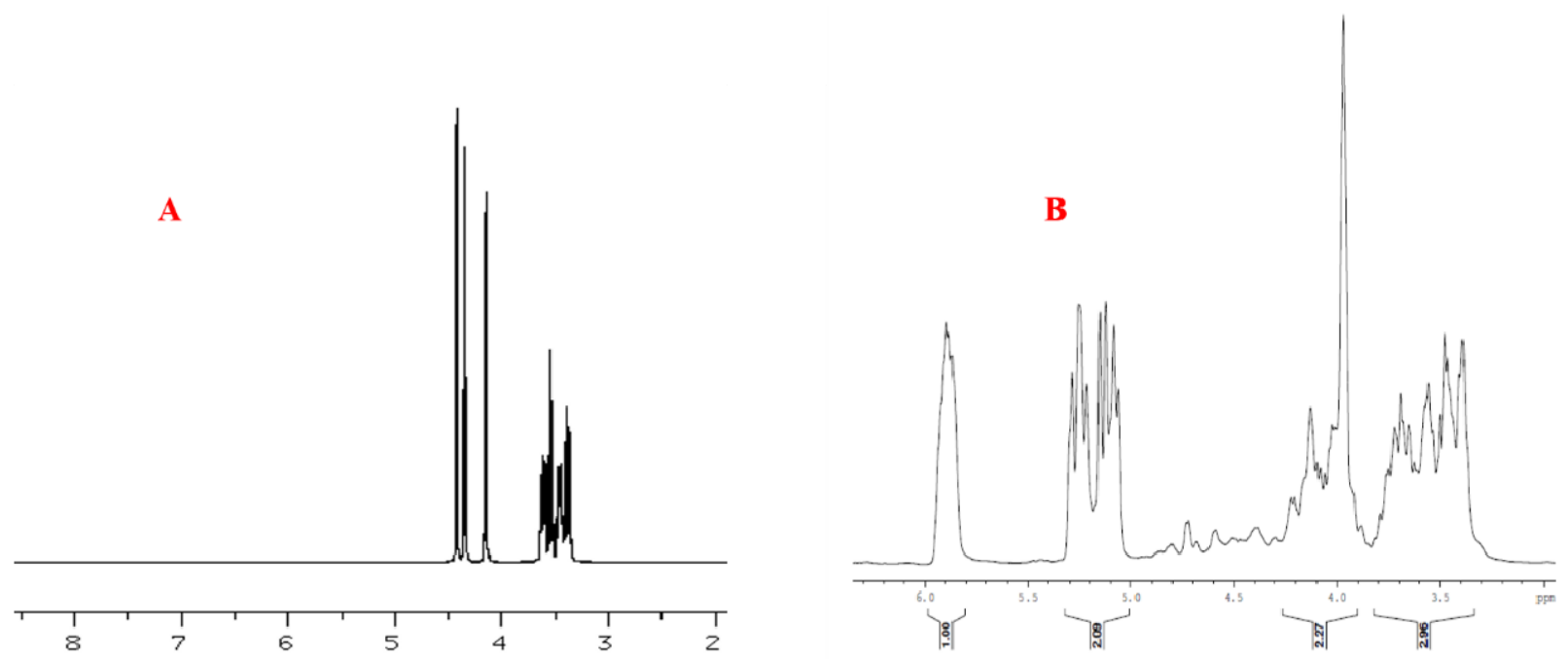

Fig. $2-{ }^{1}$ HNMR Spectra of (A) D-mannitol (B) Allyl-mannitol.

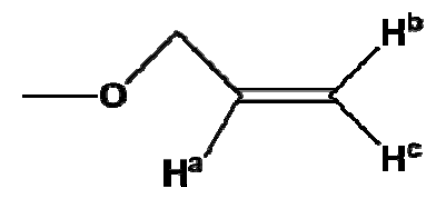

\begin{tabular}{c|c}
\hline${ }^{1}$ HNMR (in ס) & Allyl Mannitol \\
\hline $\mathrm{H}^{\mathrm{a}}$ & $6.07(\mathrm{t}, 4 \mathrm{H})$ \\
$\mathrm{H}^{\mathrm{b}}$ & $5.34(\mathrm{~d}, 4 \mathrm{H})$ \\
$\mathrm{H}^{\mathrm{c}}$ & $5.10(\mathrm{~m}, 4 \mathrm{H})$ \\
$-\mathrm{O}_{-} \mathrm{CH}_{2^{-}}$ & $4.04(\mathrm{~m}, 8 \mathrm{H})$ \\
\hline
\end{tabular}

Fig. $3-{ }^{1}$ HNMR spectra data of proton in different environment.
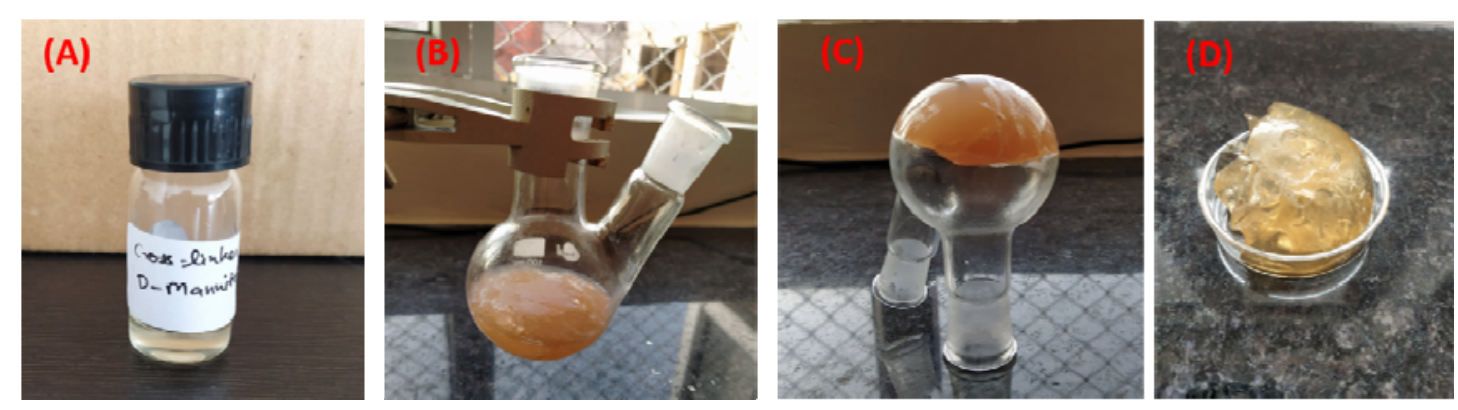

Fig. 4 - Formation of gel (B-D) with the help of cross-linker (A). 
Table 2

Swelling Capacity study at 180 minutes

\begin{tabular}{c|c|c|c|c|c}
\hline $\begin{array}{c}\text { Cross Linker } \\
\text { AM (g) }\end{array}$ & Time (min.) & $\begin{array}{c}\text { Weight of SAP } \\
\text { sample (g) }\end{array}$ & $\begin{array}{c}\text { Weight of } \\
\text { swelled SAP (g) }\end{array}$ & $\begin{array}{c}\text { Swelling capacity } \\
\text { g liquid/g SAP }\end{array}$ & $\begin{array}{c}\text { Swelling capacity } \\
\mathbf{\%}\end{array}$ \\
\hline 0.03 & 180 & 0.5 & 117.0837 & 233.1674 & 23316.74 \\
0.06 & 180 & 0.5 & 13.6335 & 26.2670 & 2626.70 \\
0.09 & 180 & 0.5 & 23.2623 & 45.5246 & 4552.46 \\
0.12 & 180 & 0.5 & 15.2282 & 29.4572 & 2945.72 \\
0.18 & 180 & 0.5 & 25.1561 & 49.3122 & 4931.22 \\
\hline
\end{tabular}

Table 3

Swelling Capacity study at 46 hours

\begin{tabular}{c|c|c|c|c|c}
\hline $\begin{array}{c}\text { Cross Linker } \\
\text { AM } \\
(\mathbf{g})\end{array}$ & Time (hour) & $\begin{array}{c}\text { Weight of SAP } \\
\text { sample (g) }\end{array}$ & $\begin{array}{c}\text { Weight of } \\
\text { swelled SAP (g) }\end{array}$ & $\begin{array}{c}\text { Swelling capacity } \\
\text { g liquid/g SAP }\end{array}$ & $\begin{array}{c}\text { Swelling capacity } \\
\%\end{array}$ \\
\hline 0.03 & & 0.5 & 141.0772 & 281.1544 & 28115.44 \\
0.06 & 46 & 0.5 & 73.4627 & 145.9254 & 14592.54 \\
0.09 & 46 & 0.5 & 61.2729 & 121.5458 & 12154.58 \\
0.12 & 46 & 0.5 & 63.6819 & 125.3638 & 12536.38 \\
0.18 & 46 & 0.5 & 60.2112 & 119.4224 & 11942.24 \\
\hline
\end{tabular}

\section{Swelling Capacity of polymer gel}

The swelling capacity of the synthesized polymeric gels were studied by tea-bag method.

Tea-Bag Method (in distilled water): The synthesized polymer gel sample $(0.5 \mathrm{~g})\left[\mathrm{W}_{0}\right]$ was placed into a pre-weighed tea bag and it was sealed. The sealed tea bag was placed in a $250 \mathrm{~mL}$ beaker filled with distilled water, and it was left for desired time (180 minutes or 46 hours) for swelling. After that the tea bag was removed from beaker, and excess amount of water was removed from swollen gel by hanging bag until, no liquid was dripping off. The swelled tea bag was weighed $\left[\mathrm{W}_{1}\right]$ and the swelling capacity of polymer gel was calculated by following equation 1 .

$$
\text { FreeSwell }=\frac{w_{1}-w_{0}}{w_{0}}
$$

The swelling capacity (SC) of synthesized polymer gel at 180 minutes and 46 hours were determined. Five different cross-linked polymer gel samples have been synthesized using different concentrations of allyl mannitol crosslinker. The swelling capacity of these polymer gel samples were calculated which are shown in Tables 2 and 3 . From the table ( 2 and 3 ), it can be seen clearly that the swelling capacity of polymer gels is high when the amount of cross linking agent (CLA) used is the lowest (i.e. $0.03 \mathrm{~g}$ crosslinker in $12.0 \mathrm{~g}$. acrylic acid monomer used during the synthesis of gel). As the amount of cross-linker (CLA) used in the synthesis of polymer gel increases, the swelling capacity (SC) of the super absorbent polymer gel (SAP) decreases.

$$
C L A \alpha \frac{1}{S C}
$$

\section{CONCLUSIONS}

A novel cross-linker, allyl mannitol has been synthesized by allylation of mannitol, using a new and easy synthetic scheme where allylation has been carried out with allyl chloride at low temperature $\left(40{ }^{\circ} \mathrm{C}\right)$ without using an autoclave. The process of the synthesis of the cross linker is very simple and convenient, and the cross-linker is eco-friendly as it is sourced from a naturally occurring sugar. In synthesis of cross linker with allyl chloride, four secondary alcoholic hydrogens of mannitol are easily replaced by allyl groups. From the spectral data (IR, ${ }^{1} \mathrm{HNMR}$ ), it has been confirmed that allyl groups are linked to Dmannitol group at four places. Cross-linked polymer gel samples have been synthesized using acrylic acid monomer and allyl mannitol crosslinker in the presence of potassium persulfate initiator. The synthesized gels show high water adsorption capacity and behave as super absorbents. The methods used in synthesis of crosslinker and polymer gel-preparation are convenient and cost effective. These hydrogels have shown promising results for their application as superabsorbent polymers. 
Acknowledgements. One of the authors (Anamica) gratefully acknowledges a research cum teaching fellowship from MMM University of Technology, Gorakhpur under Technical Education Quality Improvement Program (TEQIP), of Ministry of Human Resource Development, Government of India.

\section{REFERENCES}

1. S. Kiatkamjornwong, Science Asia, 2007, 33, 39-43.

2. G. Y. Zhou, J. M. Luo, C. B. Liu, L. Chu and J. Crittenden, Water Research, 2018, 131, 246-254.

3. S. X. Dong and Y. L. Wang, Water Research, 2016, 88, 852-860.

4. J. Wei, Z. X. Low, R. Ou, G. P. Simon and H. T. Wang, Water Research, 2016, 96, 292-298.

5. Anamica and P. P. Pande, Int. J.Mater. Sci., 2017, 12, ISSN 0973-4589.

6. D. L. Kaplan, "In Biopolymers from Renewable Resources", Germany, 1998, p. 1-29.

7. I. V. Yannas, "Natural materials. In Biomaterials Science", Academic Press California, San Diego, CA, USA, 1996, p. 84-94.
8. T. Coviello, P. Matricardi, C. Marianecci and F. Alhaiqu, J. Control. Release, 2007, 119, 5-24.

9. S. S. Stalling, S. O. Akintoye and S. B. Nicol, Acta Biomater., 2009, 5, 1911-1918.

10. R. Jin, L. S. Moreira-Teixeira, P. J. Dijstra, C. A. van Blitterswilk, M. Karperien and J. Feijen, J. Control. Release, 2011, 152, 186-195.

11. A. Makino and S. Kobayashi, J. Polym. Sci. Part A: Polym. Chem., 2010, 48, 1251-1270.

12. J. Voepel, U. Edlund and A.-C. Albertsson, J. Polym. Sci. Part A: Polym. Chem., 2009, 47, 3595-3606.

13. M. Stevenson, J. Long, A. Seyfoddin, P. Guerrero, K. de la Caba and A. Etxabide, Food Hydrocolloids, 2020, 99, 105324.

14. F. M. Karvandian, N. Shafiei, F. Mohandes, B. Dolatyar, N. Zandi, B. Zeynali and A. Simchiac, Mater. Chem. Phys., 2020, 242, 122515.

15. D. M. Hudson, M. A. Weis and D. R. Eyre, "Principles of Bone Biology", fourth edition, 2020, 339-358.

16. J. Zhang, Y. Ge, Z. Li and Y. Wang, J. Environ. Manag., 2020, 256, 109969.

17. M. D. Stelescu, E. Manaila, G. Craciun and C. Chiri, Materials, 2017, 10, 787-806.

18. A. Pourkhabbaz and H. Pourkhabbaz, Iran. J. Basic Med. Sci., 2012, 15, 636-644. 